\title{
Progress in Impurity-Related Physics Experiments in LHD
}

\author{
Shigeru MORITA, Chunfeng DONG ${ }^{1)}$, Motoshi GOTO, Masahiro KOBAYASHI, Sadatsugu MUTO, \\ Kozo YAMAZAKI ${ }^{2)}$, Masayuki YOKOYAMA, Hangyu ZHOU ${ }^{1)}$, Tsuyoshi AKIYAMA, \\ Naoko ASHIKAWA, Zhengying CUI ${ }^{3)}$, Keisuke FUJII ${ }^{4}$, Xiang GAO $^{5)}$, Masahiro HASUO ${ }^{4}$, \\ Katsumi IDA, Katsunori IKEDA, Atsushi IWAMAE ${ }^{6}$, Osamu KANEKO, Suguru MASUZAKI, \\ Junichi MIYAZAWA, Tomohiro MORISAKI, Kenichi NAGAOKA, Kazumichi NARIHARA, \\ Satoshi OHDACHI, Masaki OSAKABE, Satoru SAKAKIBARA, Ryuichi SAKAMOTO, \\ Mamoru SHOJI, Yasuhiko TAKEIRI, Kenji TANAKA, Kazuo TOI, Masayuki TOKITANI, \\ Tokihiko TOKUZAWA, Katsuyoshi TSUMORI, Kiyomasa WATANABE, Hiroshi YAMADA, \\ Ichihiro YAMADA, Jun YANAGIBAYASHI ${ }^{4)}$, Mikiro YOSHINUMA, \\ Akio KOMORI and LHD experiment group \\ National Institute for Fusion Science, Toki 509-5292, Gifu, Japan \\ ${ }^{1)}$ Department of Fusion Science, Graduate University for Advanced Studies, Toki 509-5292, Gifu, Japan \\ ${ }^{2)}$ Department of Energy Engineering and Science, Nagoya University, Nagoya 464-8603, Japan \\ ${ }^{3)}$ Southwestern Institute of Physics, Chengdu 610041, China \\ ${ }^{4)}$ Department of Engineering Physics, Kyoto University, Kyoto 606-8502, Japan \\ ${ }^{5)}$ Institute of Plasma Physics, Chinese Academy of Science, Hefei 230031, China \\ 6) Naka Fusion Institute, Japan Atomic Energy Agency, Naka 311-0193, Ibaraki, Japan
}

(Received 18 February 2010 / Accepted 6 May 2010)

\begin{abstract}
A variety of density profiles observed in the Large Helical Device (LHD) have suggested an interesting core impurity transport. The edge impurity transport in the ergodic layer formed by stochastic magnetic field lines with long connection length (10-2000 m) can also exhibit interesting phenomena in the competition of perpendicular and parallel transport. The LHD discharge is highly robust against impurity buildup, and operation is possible essentially up to the global power balance limit because current-driven instability does not principally exist. The LHD plasma has therefore provided information on many interesting physics issues closely related to impurities. Recent results of impurity-related physics experiments in the LHD are briefly reviewed. The specific contents presented here are (1) core impurity behavior with perpendicular transport, (2) edge impurity behavior with parallel transport, (3) high- $Z$ discharges with high ion temperature, (4) impurity pellet injection with improved plasma performance, (5) impurity pellet ablation in the presence of energetic ions with high heat flux and (6) observation of magnetic dipole forbidden transitions for high- $Z$ elements. A result from the Compact Helical System (CHS) is used only in the impurity pellet ablation study, because detailed data have not yet been obtained from the LHD. Finally, the results are summarized and future directions in these topics are noted.
\end{abstract}

(C) 2010 The Japan Society of Plasma Science and Nuclear Fusion Research

Keywords: impurity transport, high ion temperature, high- $Z$ discharge, impurity pellet injection

DOI: $10.1585 /$ pfr.5.S2004

\section{Introduction}

Most impurities in recent fusion devices have been represented only by carbon because of the progress in wall conditioning techniques and the replacement of plasmafacing components by carbon plates. Therefore, the impurities have not influenced the global power balance except in the edge boundary region. On the other hand, spectral line emissions from impurity ions are usually used for particle transport study, since the hydrogenic ions principally have no line emission. The production of highperformance plasmas is also possible using the intrinsic transport nature of the impurities. Recent progress in the Large Helical Device (LHD; $R /<a>=3.6 / 0.64 \mathrm{~m}$, $\left.B_{\mathrm{t}} \leq 3 \mathrm{~T}\right)$ is presented with respect to physics experiments closely related to impurities which use the passive and active methods, here called the "impurity-related physics experiments."

In the LHD, the specific type of particle transport in the plasma core is typically characterized by a variety of density profiles which differ greatly from those appearing in tokamaks, suggesting an interesting physical mechanism for core particle transport. Edge impurity transport in the ergodic layer formed by stochastic magnetic field lines with long connection lengths (10-2000 m) can also exhibit interesting phenomena, in particular, those related 
to the importance of the edge perturbation field for edge localized mode (ELM) suppression in tokamaks and the mitigation of excessive divertor heat load by active use of edge radiation.

The LHD discharge has considerable robustness against impurity buildup because the current-driven instability does not principally exist. Discharge operation up to the global power balance limit defined by the radiation loss is possible in the LHD. Therefore, pure high- $Z$ discharge with a $Z_{\text {eff }}$ value close to the atomic number is possible at least for $\mathrm{Ne}$ and $\mathrm{Ar}$, whereas $\mathrm{Ne}$ discharge in tokamaks is possible at a $\mathrm{Ne}$ ion density of $n(\mathrm{Ne}) / n_{\mathrm{e}} \sim 3 \%$, which corresponds to $Z_{\text {eff }} \sim 4$ and is limited to a relatively low density of $2 \times 10^{13} \mathrm{~cm}^{-3}[1,2]$. This robustness of the LHD also permits the production of high-performance plasmas in high- $Z$ and impurity pellet discharges.

In neutral beam injection (NBI) discharges in helical devices, the electron temperature $T_{\mathrm{e}}$ is relatively low compared with the NBI beam energy $E_{\mathrm{NBI}}$. The ratio of $T_{\mathrm{e}} / E_{\mathrm{NBI}}$ in the LHD also has a similar value to that of other small helical devices because negative-ion-source-based neutral beams with a high energy of $180 \mathrm{keV}$ are used in the LHD for tangential injection. Therefore, the beam slowing down time is longer in low-density discharges, and as a result, the heat flux of fast ions is much larger than the thermal heat flux. Impurity pellet ablation is totally dominated by the heat flux from fast ions instead of the thermal heat flux from the bulk plasma. The use of pellets is important in helical devices for maintaining a peaked density profile because of the small inward velocity. The study of pellet ablation also becomes important for improving the discharge performance. Therefore, pellet ablation has been studied in the LHD. However, clear measurement of the ablation cloud has not been successful because of the long distance between the diagnostic port and the plasma. Thus, we introduce a pellet ablation study using experimental results obtained from the Compact Helical System (CHS; $R /<a\rangle=1.0 / 0.2 \mathrm{~m}, B_{\mathrm{t}} \leq 2 \mathrm{~T}$ ).

The magnetic dipole forbidden (M1) transition has been studied extensively using an electron beam ion trap (EBIT) to construct accurate atomic structure models of high- $Z$ elements. The ITER impurity diagnostics also require experimental data on the M1 transition for high- $Z$ elements such as Mo and W, because these elements will be used in plasma-facing components. However, an extremely long exposure is required to observe the M1 transition in an EBIT because of its low emissivity. The M1 transition has also been observed using high- $Z$ discharges in the LHD.

In the present paper, specific aspects of the impurityrelated physics experiments are reviewed. The spectroscopic system necessary for the present study is explained in the references.

\section{Core Impurity Transport}

The transport coefficients predicted by neoclassical theory in the collisional regime are usually used when discussing impurities. The impurity flux $\Gamma$ and diffusion coefficient $D$ can be expressed by neoclassical theory [3] as

$$
\begin{aligned}
\Gamma_{\mathrm{q}}= & -D_{\text {imp }} \frac{\partial n_{\mathrm{q}}}{\partial r} \\
& +D_{\text {imp }} q\left(\frac{1}{n_{\mathrm{p}}} \frac{\partial n_{\mathrm{p}}}{\partial r}-\frac{1}{2}\left(1-\frac{1}{q}\right) \frac{1}{T_{\mathrm{imp}}} \frac{\partial T_{\mathrm{imp}}}{\partial r}\right) n_{\mathrm{q}}, \\
D_{\text {imp }}= & 2.24 \times 10^{-23}\left(2 q_{\mathrm{s}}^{2}+1\right) \ln \Lambda \frac{n_{\mathrm{p}}}{\sqrt{T_{\mathrm{e}}} B^{2}}\left(\mathrm{~m}^{2} / \mathrm{s}\right)
\end{aligned}
$$

and

$$
V_{\mathrm{q}}=D_{\text {imp }} q\left(\frac{1}{n_{\mathrm{p}}} \frac{\partial n_{\mathrm{p}}}{\partial r}-\frac{1}{2}\left(1-\frac{1}{q}\right) \frac{1}{T_{\mathrm{imp}}} \frac{\partial T_{\mathrm{imp}}}{\partial r}\right)(\mathrm{m} / \mathrm{s}),
$$

where $q_{\mathrm{s}}$ is the safety factor. The convective velocity $V_{\mathrm{q}}$ is understood to be proportional to the impurity charge and the gradient of the proton density $n_{\mathrm{p}}$, whereas the diffusion coefficient has no dependence on the impurity charge $q$.

The experiment is performed with a combination of a fast-response poloidal array of visible bremsstrahlung and impurity pellet injection $[4,5]$, and the transport coefficients are determined with an impurity transport code [6] by analyzing the intensity decay curves of the visible bremsstrahlung signals after impurity pellet injection. The collision frequency dependence of $D$ and $V$ is experimentally investigated at $\rho=0.8$. The result is plotted in Fig. 1 for carbon, aluminum and titanium ions. The collision frequency is normalized by that at the boundary between the plateau and collisional (Pfirsch-Schlüter) regimes $\left(v_{\mathrm{p}} \equiv v_{\text {imp }} / R q_{\mathrm{s}}\right)$. This result suggests that the diffusion coefficients have no dependence on the impurity charge and electron density. The inward convective velocities, however, clearly indicate a dependence on the collision frequency. Note that these results do not agree well with the neoclassical theory. The impurity transport coefficients of carbon have been examined for different fuel ions of hydrogen and helium [7]. The diffusion coefficients of hydrogen and helium plasmas were found to be the same. The inward velocities of hydrogen plasmas, however, are larger by a factor of two than those of helium plasmas.

The effect of the ion density gradient on the inward velocity is examined at $\rho=0.8$, as shown in Fig. 2. Since a flat $Z_{\text {eff }}$ profile is observed in most discharges [8-10], the electron density profile reflects the ion density profile. The inward velocity is a strong function of the density gradient, $\partial n_{\mathrm{e}} / \partial r$, whereas the dependence on $\partial n_{\mathrm{e}} / n_{\mathrm{e}} \partial r$ is quite weak. The inward velocity of carbon is also plotted for helium plasmas. Half values are used for the helium plasmas against the horizontal axis, because the helium is doubly ionized. 


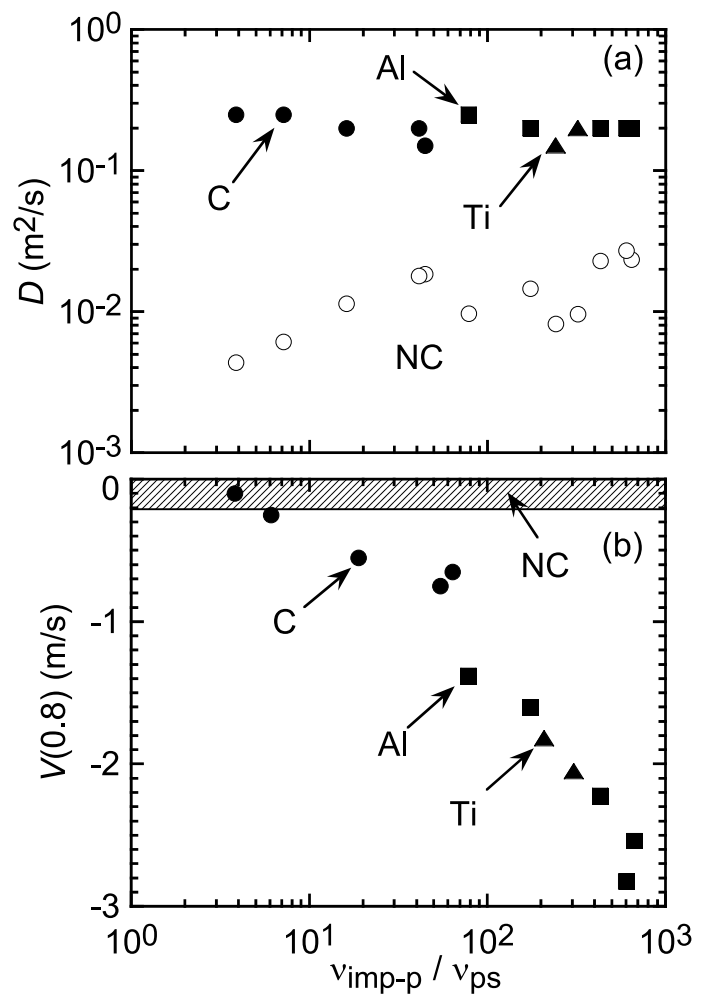

Fig. 1 (a) Diffusion coefficient and (b) convective velocity at $\rho=$ 0.8 versus impurity collision frequency with protons normalized by frequency $v_{\mathrm{PS}}$ at the boundary between the plateau and Pfirsch-Schlüter regimes. Neoclassical diffusion coefficients (NC) are indicated by open circles and hatched area.

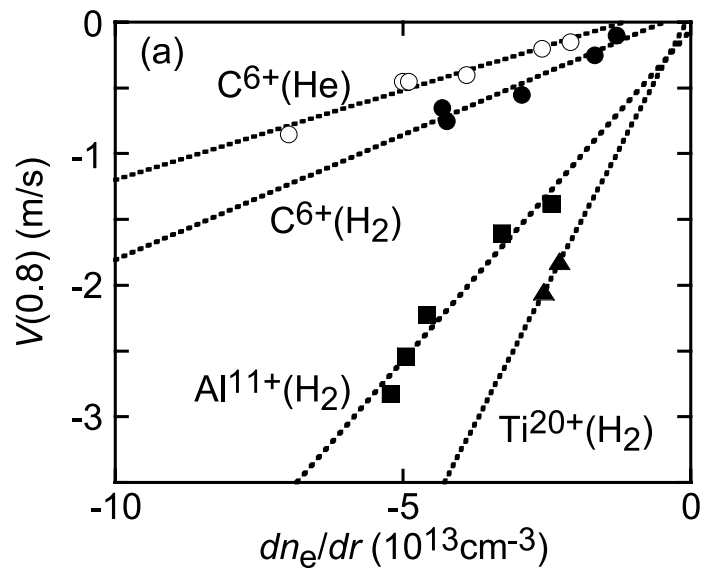

Fig. 2 Dependence of convective velocity at $\rho=0.8$ on electron density gradient in $\mathrm{H}_{2}$ (solid circles: $\mathrm{C}^{6+}$, solid squares: $\mathrm{Al}^{11+}$, solid triangles: $\mathrm{Ti}^{20+}$ ) and $\mathrm{He}$ (open circles: $\mathrm{C}^{6+}$ ) plasmas.

\section{Edge Impurity Transport}

Edge impurity transport can be explained by a simple one-dimensional model of transport parallel and perpendicular to the field lines $[11,12]$. Impurity transport along

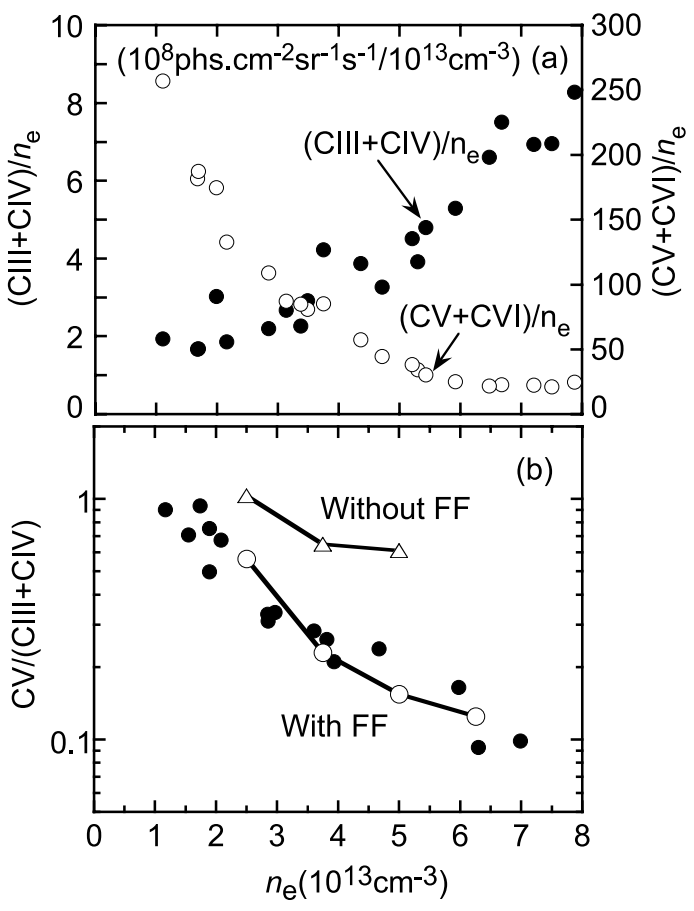

Fig. 3 (a) Normalized intensities of $(\mathrm{CV}+\mathrm{CVI}) / n_{\mathrm{e}}$ (open circles) and (CIII $+\mathrm{CIV}) / n_{\mathrm{e}}$ (closed circles) in units of $10^{8}$ photons $\mathrm{cm}^{-2} \mathrm{sr}^{-1} \mathrm{~s}^{-1} / 10^{13} \mathrm{~cm}^{-3}$ as a function of lineaveraged density for $R_{\mathrm{ax}}=3.6 \mathrm{~m}$. (b) Intensity ratios of $\mathrm{CV}$ to CIII + CIV from experiment (closed circles) and simulation with (open circles + solid line) and without (open triangles + solid line) friction force as a function of line-averaged density.

the field lines is expressed by the momentum equation

$$
\begin{aligned}
m_{\mathrm{z}} \frac{\partial V_{\mathrm{z} \|}}{\partial t}= & -\frac{1}{n_{\mathrm{z}}} \frac{\partial T_{\mathrm{i}} n_{\mathrm{z}}}{\partial s}+m_{\mathrm{z}} \frac{V_{\mathrm{i} \|}-V_{\mathrm{z} \|}}{\tau_{\mathrm{zi}}}+Z e E_{\|} \\
& +0.76 Z^{2} \frac{\partial T_{\mathrm{e}}}{\partial s}+2.6 Z^{2} \frac{\partial T_{\mathrm{i}}}{\partial s},
\end{aligned}
$$

where the subscripts $z$ and $i$ denote impurity ions with a charge state $Z$ and background ions, respectively, and $\tau_{\mathrm{zi}}$, $E_{\|}$, and $V_{\|}$denote the impurity-ion collision time, parallel electric field, and parallel flow velocity, respectively. The parameter $s$ is the coordinate along the field line. The force balance between the FF (the second term: the friction between impurity and background ions) and the FIG (the fifth term: the ion temperature gradient) finally defines the direction of the impurity flow. Here, the FIG drives the impurity ions to the higher-temperature region (upstream), and the FF drives them to the divertor (downstream).

The line intensities of carbon ions have been measured using an extreme ultraviolet (EUV) spectrometer [13-15]. The result is plotted in Fig. 3 (a) as a function of lineaveraged density. The CIII and CIV emission increases with $n_{\mathrm{e}}$, whereas the $\mathrm{CV}$ emission decreases with $n_{\mathrm{e}}$. CIII and CIV are located at $T_{\mathrm{e}} \leq 15 \mathrm{eV}$ outside the ergodic layer of the LHD. CV is located at $15 \mathrm{eV} \leq T_{\mathrm{e}} \leq 100 \mathrm{eV}$ near the last closed flux surface (LCFS). Therefore, CIII and CIV can serve as an index representing the source term, and CV 
can represent ions which have already experienced transport in the ergodic layer. Thus, the intensity ratio of $\mathrm{CV}$ to CIII + CIV represents the degree of impurity screening [16]. The results are shown in Fig. 3 (b). Impurity screening with density in the LHD is clearly demonstrated. Edge impurity transport is simulated using the three-dimensional edge transport code EMC3-EIRENE [12]. The results are also indicated in the figure. They are normalized to the experimental data at $n_{\mathrm{e}}=3.7 \times 10^{19} \mathrm{~m}^{-3}$, as indicated by "With FF." The $n_{\mathrm{e}}$ dependence on the ratios shows good qualitative agreement between the experiment and the simulation. The case of no friction force is also simulated and is plotted in the figure as "Without FF." The ratio of CV to CIII + CIV does not decrease with the density. The role of the friction force becomes apparent when the friction force term is turned off during the simulation [17]. The radial profile of the impurity emissions has been recently observed [18], and further comparison with the experimental data will be soon done.

\section{High-Z Discharges with High Ion Temperature}

High- $Z$ discharges have been attempted to achieve higher ion temperatures [19-22]. An increase in $P_{\mathrm{i}} / n_{\mathrm{i}}$ attributed to the reduction in $n_{\mathrm{i}}$ was expected in the high- $Z$ NBI discharge. The central ion temperature is measured from Doppler broadening of the ArXVII (3.9492 А) x-ray line [23]. Ar discharges were attempted by repeating He, $\mathrm{Ne}$ or Ar glow discharge cleaning, with the expectation of further decreases in hydrogen ion density. The $T_{\mathrm{i}}$ measured during the steady phase of the discharges is plotted in Fig. 4 (a) against the density peaking factor, which is shown by the ratio of the density at the plasma center to that at $\rho=0.8$. The density profile is peaked in the $\mathrm{Ar}$ discharges, suggesting a relatively low recycling rate of $\mathrm{Ar}$ atoms compared to that of $\mathrm{Ne}$ atoms. A difference in density peaking is also visible between the $\mathrm{He}$ and $\mathrm{Ne}$ glow discharge cleanings, which were done before the experiment [24]. The He glow discharge cleaning produces a slightly higher peak in the density profile. In the Ar discharges, the central ion temperature depends strongly on the density peaking as seen in Fig. 4 (a).

The toroidal rotation at the plasma center is also compared with the central ion temperature. A good correlation is observed between the two in Ar discharges, as shown in Fig. 4(b). The maximum toroidal rotation velocity of $40 \mathrm{~km} / \mathrm{s}$ obtained in the Ar discharges reaches $30 \%$ of the Ar thermal velocity with $T_{\mathrm{i}}(0)=7 \mathrm{keV}$. This large toroidal rotation is of course produced by the momentum input from tangential NBIs. However, whether the enhancement of the toroidal rotation contributes greatly to the increase in ion temperature [25] is yet to be found, whereas the relationship between the toroidal rotation and the density peaking is quite reasonable, as described later. In contrast, no large toroidal rotation is observed in the Ne discharges,
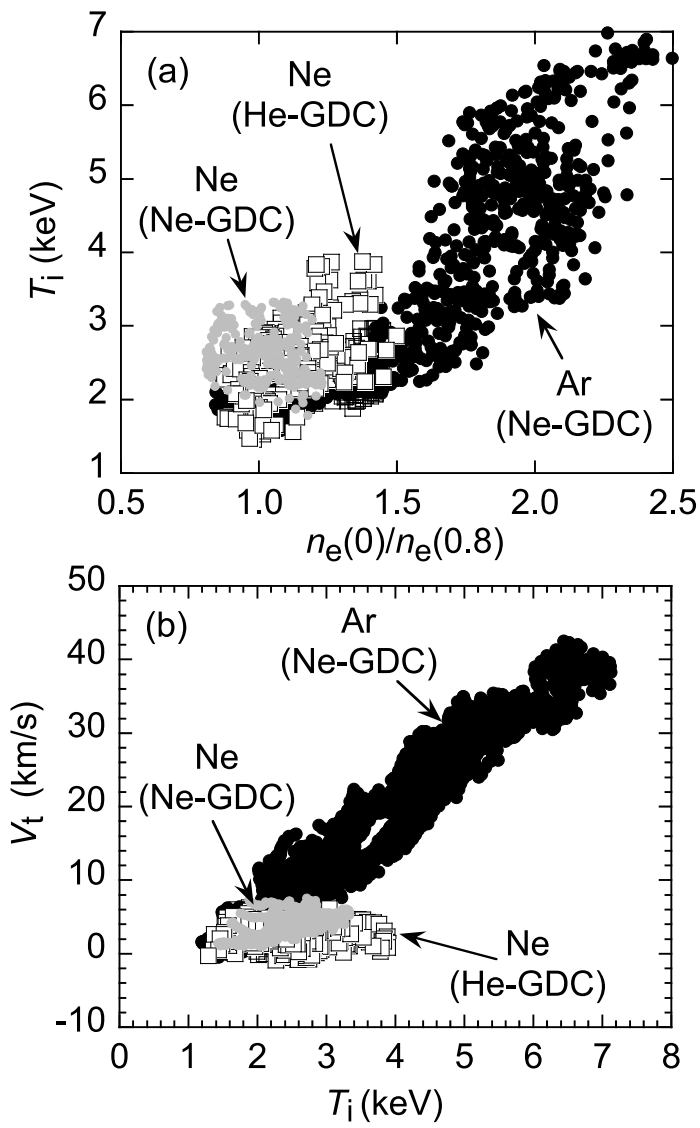

Fig. 4 (a) Central ion temperature as a function of density peaking factor and (b) central toroidal rotation velocity as a function of central ion temperature in Ne discharge after $\mathrm{He}$ (open squares) and $\mathrm{Ne}$ (gray closed circles) glow discharge cleaning and Ar discharge after Ne glow discharge cleaning (black closed circles). Density peaking factor is defined by the ratio of the densities at $\rho=0$ and $\rho=0.8$.

although the central ion temperature reaches $4 \mathrm{keV}$. The remarkable difference between the $\mathrm{Ar}$ and Ne discharges lies only in the density profile.

Ion transport in high- $Z$ discharges is analyzed by comparing the two typical discharges with $\mathrm{Ne}$ and $\mathrm{Ar}$, on the basis of the TOTAL code combined with the impurity transport code $[26,27]$. The temperature and density profiles used in the present analysis, which are measured with Thomson and far-infrared (FIR) diagnostics, respectively, are shown in Figs. 5 (a) and (b). The ion temperature profiles are not measured because strong $\mathrm{Ne}$ and $\mathrm{Ar}$ spectral lines exist in the wavelength range to be observed by charge exchange recombination spectroscopy. Thus, those profiles are estimated from a combination of Doppler measurements by X-ray crystal, vacuum ultraviolet (VUV) and visible spectroscopy using the magnetic dipole forbidden (M1) transition (see section 7).

The ion thermal diffusivity is plotted with the electron thermal diffusivity in Fig. 5 (c) at $0.2 \leq \rho \leq 0.8$. In the analysis, $Z_{\text {eff }}(\mathrm{Ne})=8.5, n(\mathrm{Ne})=0.083 n_{\mathrm{e}}$, and $n(\mathrm{H})$ $=0.17 n_{\mathrm{e}}$ are used for the Ne discharge, and $Z_{\mathrm{eff}}(\mathrm{Ar})=15$, 

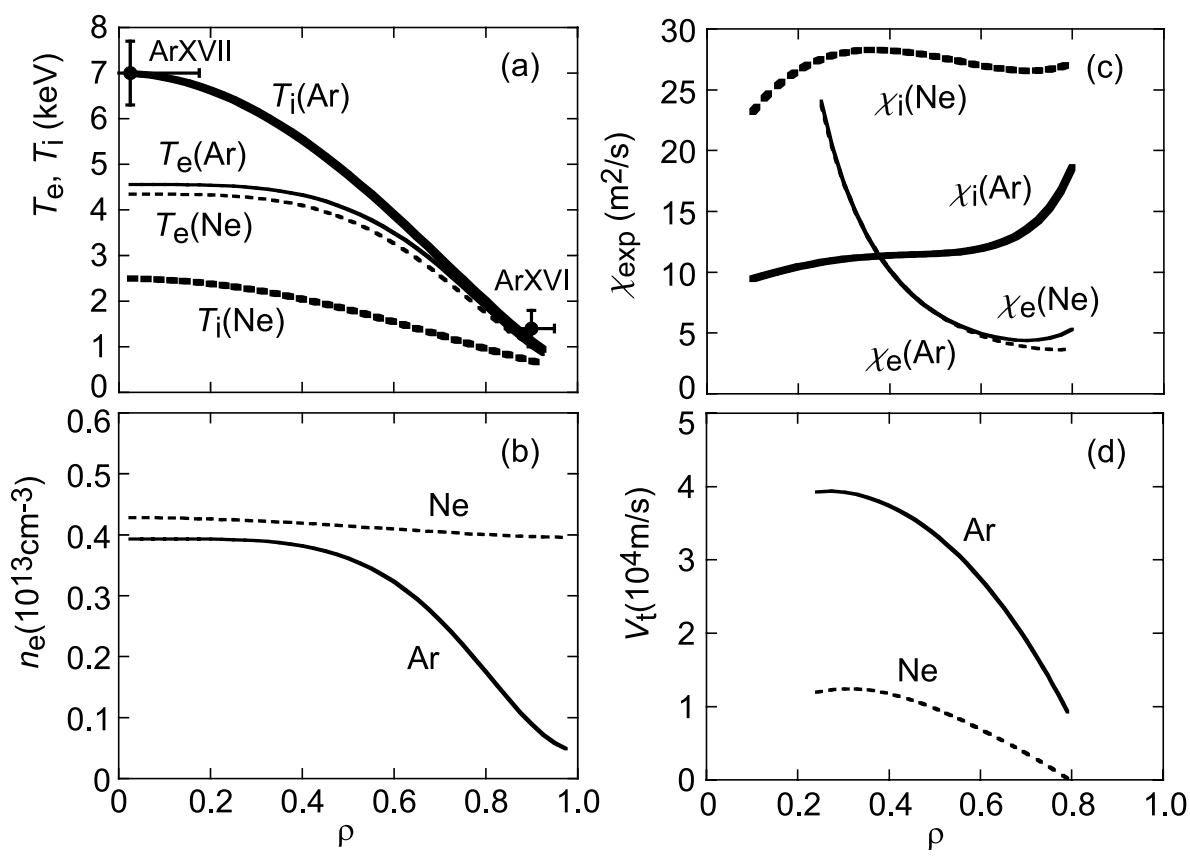

Fig. 5 (a) $T_{\mathrm{i}}(\rho)$ in $\mathrm{Ar}$ (thick solid line) and $\mathrm{Ne}$ (thick dashed line) discharges and $T_{\mathrm{e}}(\rho)$ in $\mathrm{Ar}$ (thin solid line) and Ne (thin dashed line) discharges. (b) $n_{\mathrm{e}}(\rho)$ in $\mathrm{Ar}$ (solid line) and $\mathrm{Ne}$ (dashed line) discharges. (c) Ion thermal diffusivities, $\xi_{\mathrm{i}}(\rho)$, in $\operatorname{Ar}$ (thick solid line) and $\mathrm{Ne}$ (thick dashed line) discharges and electron thermal diffusivities, $\xi_{\mathrm{e}}(\rho)$, in Ar (thin solid line) and $\mathrm{Ne}$ (thin dashed line) discharges. (d) Toroidal rotation velocity $V_{\mathrm{t}}(\rho)$ in $\mathrm{Ar}$ (solid line) and $\mathrm{Ne}$ (dashed line) discharges. Ion temperatures are measured at the plasma's center (ArXVII) and edge (ArXVI).

$n(\mathrm{Ar})=0.046 n_{\mathrm{e}}$, and $n(\mathrm{H})=0.17 n_{\mathrm{e}}$ are used for the Ar discharge. Of course, the results are very sensitive to the value of $Z_{\text {eff }}$ or the remaining hydrogen density. It is difficult to measure $Z_{\text {eff }}$ using the usual method based on the visible bremsstrahlung. The value of $Z_{\text {eff }}$ used in the calculation is determined by the impurity spectroscopy and the $\mathrm{H} \alpha$ intensity in the recombination phase after NBI was turned off. If we simply describe the sensitivity of $\chi_{\mathrm{i}}$ to $Z_{\mathrm{eff}}$, it increases linearly when the impurity density reduces. The ion thermal diffusivity is quite large even in the high-temperature plasma in the Ar discharge. The value is several times larger than that in hydrogen discharges $\left[T_{\mathrm{i}}(0) \sim 2-3 \mathrm{keV}\right.$ and $\chi_{\mathrm{i}}(\mathrm{H}) \sim 2-5 \mathrm{~m}^{2} / \mathrm{s}$ at $\left.n_{\mathrm{e}} \sim 1-2 \times 10^{13} \mathrm{~cm}^{-3}\right]$. The total ion density in the Ar discharges, $n_{\text {i_tot }}(\mathrm{Ar})$, is much less than that in the hydrogen discharges, $n_{\text {i_tot }}(\mathrm{H})$, which is assumed to be $Z_{\text {eff }}=1.5-2.0$, i.e., $n_{\text {i_tot }}(\operatorname{Ar}) / n_{\text {i_tot }}(\mathrm{H}) \sim$ 0.25 . Since the collisionality in the Ar plasma stays in the plateau regime $\left(v_{\mathrm{p}}^{*} \sim 0.1\right)$ at the plasma center, ripple transport is still important even for such high- $Z$ elements.

The toroidal rotation is also analyzed under the same parameters using the SPBSC code [28]. The result is shown in Fig. 5(d). The calculated rotation agrees well with the experimentally observed values. The enhanced toroidal rotation seen in the Ar discharge is caused by a reduction in the edge viscosity originating in a density reduction at the outer region of the plasma. Therefore, the density profile as well as the magnetic field ripple structure plays an important role in the toroidal rotation.

\section{Plasma Performance Improvement by Impurity Pellet Injection}

In the LHD, extensive experiments on hydrogen pellet injection have been performed in relation to the study of high-density operation with improved plasma performance because current-driven instability can be essentially ruled out [29]. Impurity pellets with atomic numbers of $Z=6$ 74 have also been injected into the LHD plasmas, and the plasma response has been studied in low- and high-density regions.

The size and speed of the injected cylindrical or spherical pellets range from $0.3-1.8 \mathrm{~mm}$ depending on $Z$, and $100-300 \mathrm{~m} / \mathrm{s}$ depending on the weight and size, respectively [30]. Heavier pellets generally have a lower speed. The plasma response has been investigated after pellet injection in relation to the possible density increase against $Z$ by systematically changing $Z$ ( $\mathrm{H}, \mathrm{C}, \mathrm{Al}, \mathrm{Ti}, \mathrm{Fe}, \mathrm{Mo}, \mathrm{Sn}$, and $\mathrm{W}$ ). The results are shown in Figs. 6 (a) and (b), respectively. The maximum size of the pellets with which the discharge can be maintained without plasma collapse under $P_{\text {in }} \sim 10-18 \mathrm{MW}, S_{\max }$, is $3.4 \mathrm{~mm}^{\phi} \times 3.4 \mathrm{~mm}^{\mathrm{L}}$ in a cylinder for an $\mathrm{H}_{2}$ ice pellet and $1.8 \mathrm{~mm}^{\phi} \times 1.8 \mathrm{~mm}^{\mathrm{L}}$ in a cylinder for a carbon pellet. The largest pellets, $3.8 \mathrm{~mm}$ $\mathrm{H}_{2}$ and $2.0 \mathrm{~mm}$ carbon pellets, were used in the LHD, but smooth discharge operation was slightly difficult. $S_{\max }$ decreases when $Z$ increases; $S_{\max } \sim 1 \mathrm{~mm}$ for $\mathrm{Al}$ and Ti and $0.2-0.3 \mathrm{~mm}$ for Mo and $\mathrm{W}$. The maximum density increase $\Delta n_{\mathrm{e}}$ is close to $1 \times 10^{14} \mathrm{~cm}^{-3}$ for single-pellet injection of both $\mathrm{H}_{2}$ and carbon pellets. However, the upper limit of 


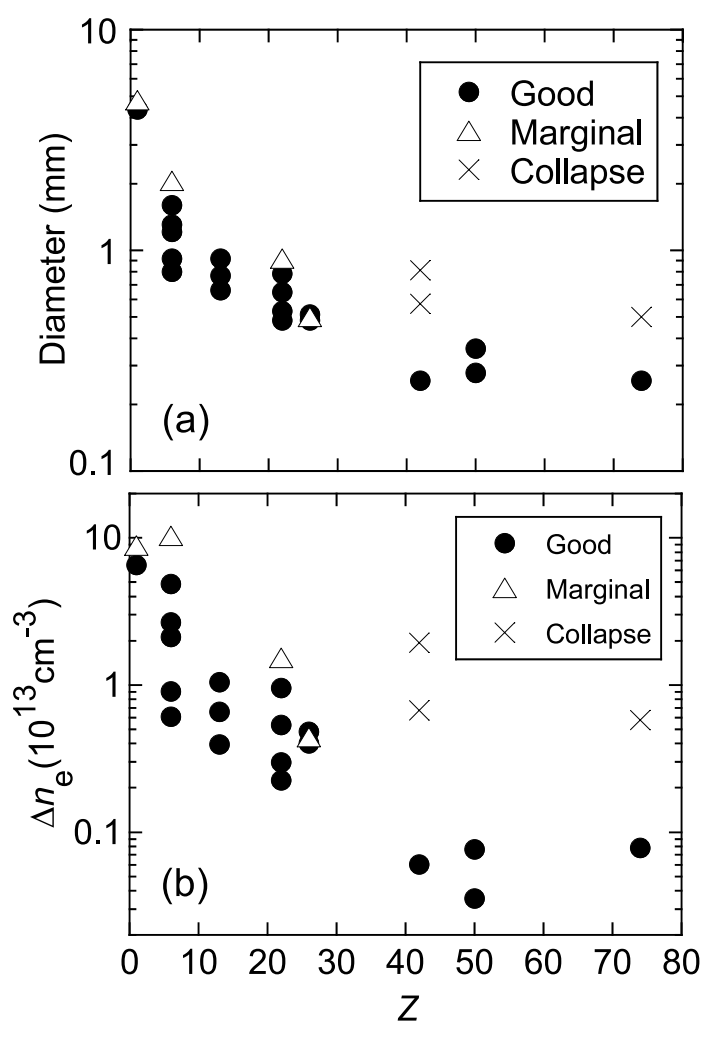

Fig. 6 Plasma response after injection of $\mathrm{H}, \mathrm{C}, \mathrm{Al}, \mathrm{Ti}, \mathrm{Fe}, \mathrm{Mo}$, $\mathrm{Sn}$, and $\mathrm{W}$ pellets. (a) Diameters of injected pellets and (b) density increase as a function of atomic number $Z$. Discharges without and with collapse after pellet injection are denoted with solid circles and crosses, respectively, and triangles represent discharges with a large reduction in plasma stored energy without collapse.

$\Delta n_{\mathrm{e}}$ was reduced to $1 \times 10^{13} \mathrm{~cm}^{-3}$ for Al pellets.

The plasma performance after carbon pellet injection is compared at $R_{\mathrm{ax}}=3.60 \mathrm{~m}$ with that after gas puffing and $\mathrm{H}_{2}$ pellet injection in Fig. 7. $W_{\mathrm{p}}$ is scaled by the stellarator scaling of ISS95 to compensate for the difference in NBI input power (5 MW $\left.\leq P_{\mathrm{NBI}} \leq 18 \mathrm{MW}\right)$. The maximum $W_{\mathrm{p}}$ observed during the density decay phase is also plotted. Multi-pellet injection is done for $\mathrm{H}_{2}$ pellets, whereas single pellets are used for carbon pellet injection. The operational range with high $W_{\mathrm{p}}$ is therefore different between the two pellets (C: $2-4 \times 10^{13} \mathrm{~cm}^{-3}, \mathrm{H}_{2}: 4-10 \times 10^{13} \mathrm{~cm}^{-3}$ ). In the LHD, improved confinement in hydrogen discharges has been observed so far by comparison with the ISS95 scaling, as indicated by " $1.5 \times$ ISS95" [31]. The performance of the present carbon pellet injection also demonstrates confinement properties similar to those of $\mathrm{H}_{2}$ pellets [32].

A mid-size cylindrical carbon pellet $\left(1 \mathrm{~mm}^{\phi} \times 1 \mathrm{~mm}^{\mathrm{L}}\right)$ has been injected in Ne discharges [33]. Typical waveforms are traced in Fig. 8. A density of $n_{\mathrm{e}}=0.4-0.5 \times$ $10^{13} \mathrm{~cm}^{-3}$ is maintained by neon puffing and recycled hydrogen. The central ion temperature increases gradually and reaches $5 \mathrm{keV}$ after carbon pellet injection. Note that

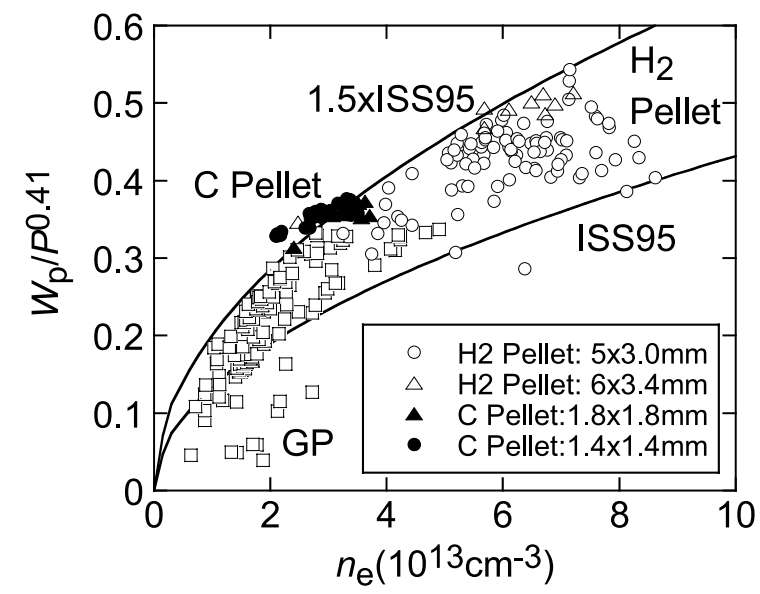

Fig. 7 Plasma performance with carbon pellet injection (solid circles and triangles) normalized by ISS95 input power scaling $\left(W_{\mathrm{p}}[\mathrm{MW}], P[\mathrm{MW}]\right)$. Results after hydrogen pellet injection and gas puffing are denoted by open circles and triangles and open squares, respectively.

the temperature decay after NBI, turned off at $t=2.5 \mathrm{~s}$, is remarkably long. The carbon pellet is injected before turning on NBIs \#2 and \#3 to avoid ablation in the outer plasma region and achieve central particle deposition. This was crucial to increase the ion temperature after carbon pellet injection. The density profiles are entirely peaked with peaking factors up to $\sim 2.5$, followed by an increase in toroidal rotation as large as that in the Ar discharge. The Ne discharge can also yield high performance with a change in the density profile after carbon pellet injection.

\section{Impurity Pellet Ablation by Ener- getic Ions with High Heat Flux}

In the LHD, the beam energy takes a very long time to slow down, particularly in the low-density range because of the high beam energy, i.e., $180 \mathrm{keV}$. The slowing down time is ten times longer than the energy confinement time in the low-density range, although they are equal at $n_{\mathrm{e}}=$ $4 \times 10^{13} \mathrm{~cm}^{-3}$. Because of the long slowing down time, the beam energy stored in the plasma is also large. Therefore, the heat flux of the NBI fast ions becomes extremely large in low-density the LHD operation. The beam heat flux $Q_{\mathrm{NBI}}$ is much larger than the thermal heat flux $Q_{\mathrm{p}}$ over quite a wide density range. In particular, the ratio is extremely high $\left(Q_{\mathrm{NBI}} / Q_{\mathrm{p}} \geq 10\right)$ in the density range of $n_{\mathrm{e}} \leq$ $3 \times 10^{13} \mathrm{~cm}^{-3}$. This high beam heat flux influences the impurity pellet ablation remarkably in relatively low-density discharges.

The effect of the beam heat flux on pellet ablation is introduced using an experiment in the CHS [34], since no clear effect on the ablation cloud has been successfully observed yet in the LHD because of the geometrical difficulty. In the CHS, two tangential neutral beams $\left(P_{\mathrm{NBIH1}}+P_{\mathrm{NBI} I 2}\right.$ $=1.0 \mathrm{MW}+1.0 \mathrm{MW})$ are installed for balanced injection 

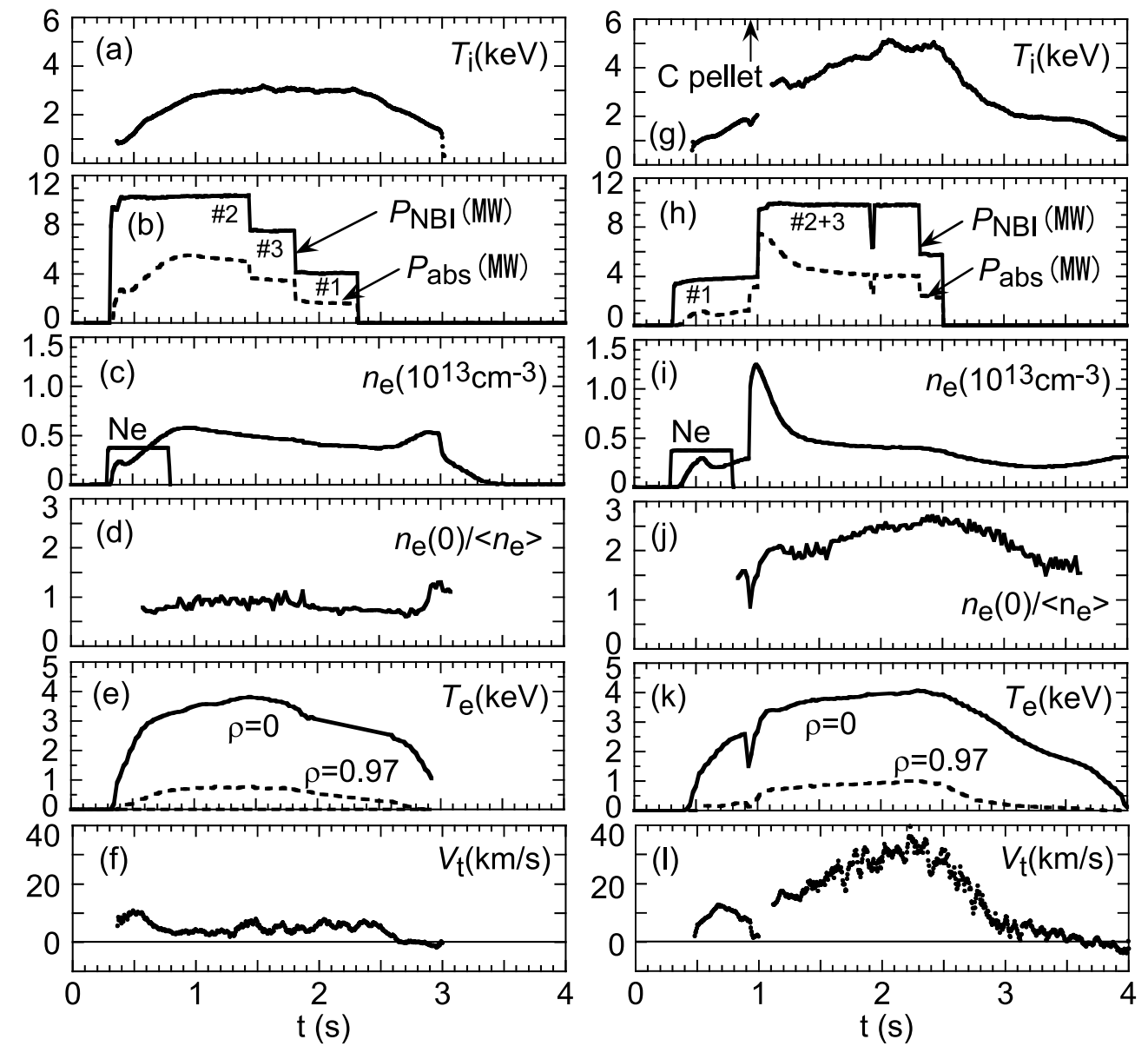

Fig. 8 Ne-seeded discharges without (left) and with (right) carbon pellet injection. (a) and (g) Central ion temperature, (b) and (h) NBI power (solid: port-through power, dashed: absorption power), (c) and (i) line-averaged electron density (Ne: neon gas puff), (d) and (j) density peaking factor $\left[n_{\mathrm{e}}(0)\right.$ : central electron density, $\left\langle n_{\mathrm{e}}\right\rangle$ : line-averaged electron density], (e) and (k) electron temperature, and (f) and (l) central toroidal rotation speed.

to cancel out the beam-driven current. As the beam energy of $40 \mathrm{keV}$ is also sufficiently high compared to the electron temperature, the beam heat flux is much larger than the thermal heat flux, as in the LHD. Hydrocarbon pellets with a diameter of $0.32 \mathrm{~mm}$ were used for the experiment, as in an earlier study on disruption control in a tokamak [35].

The pellet was first injected into electron cyclotron heating $(\mathrm{ECH})$ plasmas, and two CCD images of the ablation cloud were made from the top and side of the plasma through an interference filter $\left[\lambda_{0}=538 \mathrm{~nm}\right.$, full width at half maximum $(\mathrm{FWHM})=2 \mathrm{~nm}$ ] to measure the visible CI line. The result is shown in Fig. 9 (a). The pellet trajectory is straight and no deviation is observed, although the size of the cloud grows with the penetration depth.

The pellet was also injected into NBI plasmas to clarify the effect of fast ions on pellet ablation. The electron density is adjusted to the same level $\left(1 \times 10^{13} \mathrm{~cm}^{-3}\right)$ as in the ECH plasma. The result is shown in Fig. 9 (b). The fast ions move from left to right. The ablated pellet trajectory curves toward the toroidal direction of the fast ions, and it also curves poloidally, as shown in the side view. The poloidal angle between the equatorial plane and the pellet trajectory agrees well with the pitch angle $\left\{=\tan ^{-1}[(r / R) \times\right.$ $(\iota / 2 \pi)]\}$ of the magnetic field lines, e.g., $3^{\circ}$ at $\rho=0.5$ and $13^{\circ}$ at $\rho=1.0$. The poloidal angle estimated from the figure is $3.5 \pm 0.5^{\circ}$. This angle coincides with the pitch angle of the magnetic field lines at $\rho \sim 0.5$. This result strongly supports the presence of pellet ablation by fast ions. Next, the direction of the fast ions is changed so that they move from right to left. The result is shown in Fig. 9 (c). Unlike the previous case, the pellet is strongly ablated at the outer region of the plasma and starts to curve after passing through half the radius of the plasma. These pictures more clearly demonstrate that the pellet is ablated by fast ions.

It is clear from Fig. 10 (a) that the pellet velocity increases from $270 \mathrm{~m} / \mathrm{s}$ at the plasma edge to $600 \mathrm{~m} / \mathrm{s}$ near the plasma center, whereas the velocity is constant in the ECH case. The acceleration of the pellet is $2 \times 10^{5} \mathrm{~m} / \mathrm{s}^{2}$ at the plasma edge and is constant until $\rho=0.4$, as shown in Fig. 10 (b). When the pellet penetrates the plasma more deeply, the acceleration increases monotonically and reaches $1.2 \times 10^{6} \mathrm{~m} / \mathrm{s}^{2}$ at $\rho=0.25$, where the pellet disappears. After the pellet passes through the radial location of $\rho=0.4$, its direction changes to parallel to the magnetic 
(a) $\mathrm{ECH}$

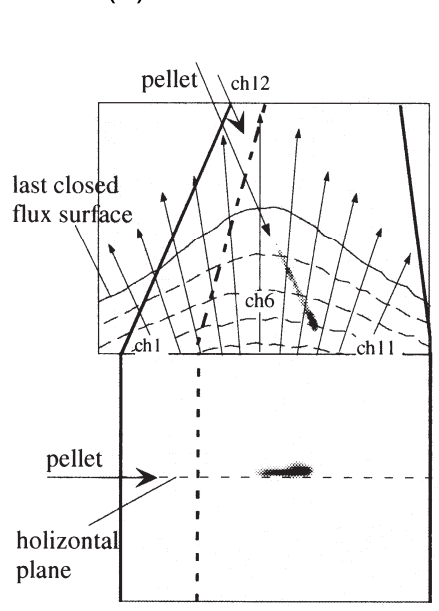

(b) NBI\#1

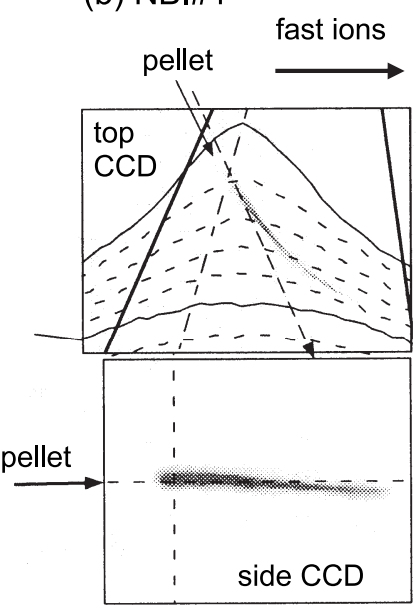

(c) NBI\#2

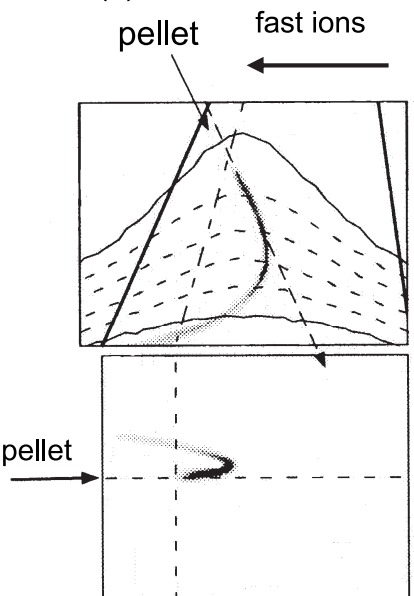

Fig. 9 CCD images of pellet trajectory observed in the CHS (top: horizontal view, side: poloidal view). (a) ECH, (b) NBI\#1, and (c) NBI\#2. Arrows ch1-ch11 indicate view chords of the CI horizontal array, and arrow ch12 indicates CI monitor at back side of pellet injection.

field lines. The size of the pellet cloud takes a maximum value at $\rho=0.7$, i.e., a radial size $\left(=L_{\mathrm{r}}\right)$ of $18 \mathrm{~mm}$ and a toroidal size $\left(=L_{\mathrm{t}}\right)$ of $21 \mathrm{~mm}$ [see Fig. $10(\mathrm{c})$ ]. With deep penetration into the plasma, the cloud becomes smaller $\left(L_{\mathrm{r}}\right.$ $=14 \mathrm{~mm}$ and $L_{\mathrm{t}}=12 \mathrm{~mm}$ at $\rho=0.5, L_{\mathrm{r}}=7 \mathrm{~mm}$ and $L_{\mathrm{t}}=$ $6 \mathrm{~mm}$ at $\rho=0.25)$.

The pellet is accelerated by a unidirectional jet of the pellet ablation cloud. The acceleration is expressed by

$$
\left.\alpha=P \times \pi r^{2} /\left[(4 / 3) \pi r^{3} \times \rho_{\mathrm{P}}\right)\right] \propto P / r,
$$

where $P(=n k T)$ is the fast ion pressure, $\rho_{\mathrm{P}}(=1.05 \times$ $\left.10^{-3} \mathrm{~g} / \mathrm{mm}^{3}\right)$ is the density of the pellet, and $r(=0.16 \mathrm{~mm})$ is the radius of the pellet. Assuming steady pellet ablation, the jet density necessary for this acceleration is given by

$$
n=N / v \times \Delta t \times \pi r^{2},
$$

where $N\left(=8.5 \times 10^{17}\right)$ is the total number of pellets, $v$ is the velocity of the jet, and $\Delta t(=1 \mathrm{~ms})$ is the ablation time. Assuming a jet temperature of $2000 \mathrm{~K}$ corresponding to $v=1.7 \times 10^{3} \mathrm{~m} / \mathrm{s}$ [36], we obtain a jet density of $6.2 \times 10^{18} \mathrm{~cm}^{-3}$. Using this jet density and temperature, a pressure of $1.7 \times 10^{5} \mathrm{~N} / \mathrm{m}^{2}$ is derived. Thus, we finally calculate an acceleration of $7.6 \times 10^{5} \mathrm{~m} / \mathrm{s}^{2}$. By calculating the direct momentum input from the fast ions, the acceleration is estimated to be $2 \times 10^{4} \mathrm{~m} / \mathrm{s}^{2}$. Therefore, this effect can be ignored.

\section{Magnetic Dipole Forbidden Transi- tion}

The solution of the time-dependent unperturbed Schrödinger equation is

$$
i \hbar \frac{\partial \Psi_{k}}{\partial t}=H_{0} \Psi_{k}
$$

Introducing the time-independent eigenfunctions $\psi_{k}$ and eigenvalues $E_{k}$ yields

$$
\Psi_{k}=\psi_{k}(\boldsymbol{r}) \exp \left(-i E_{k} t / \hbar\right)
$$

where $\psi_{k}$ is the sum over the complete set of eigenfunctions. Using the classical vector potential, the matrix elements are defined as

$$
\left\langle\psi_{b}|\exp (i \boldsymbol{k} \cdot \boldsymbol{r}) \hat{\boldsymbol{\varepsilon}} \cdot \nabla| \psi_{a}\right\rangle,
$$

where $\hat{\varepsilon}$ is the unit vector for radiation polarization, and $k$ is the propagation vector of the radiation. The values of $a$ and $b$ denote the initial and final states of the transition. The exponential of $\exp (i k \cdot r)$ can thus be expanded as

$$
\exp (i \boldsymbol{k} \cdot \boldsymbol{r})=1+(i \boldsymbol{k} \cdot \boldsymbol{r})+\frac{1}{2 !}(i \boldsymbol{k} \cdot \boldsymbol{r})^{2}+\cdots .
$$

If the quantity $k r$ is small $\left(k \sim 10^{-3} \AA\right.$ and $r<10 \AA$ in a typical atom), the exponential can be replaced by unity. This is known as the electric dipole $(\mathrm{E} 1: \Delta \ell= \pm 1)$ transition and is usually observed in plasma spectroscopy. If the higher terms in the series in Eq. (10) are not negligible, the transition changes to the magnetic dipole (M1: $\Delta n=$ 0 and $\Delta \ell=0)$ and electric quadrupole (E2: $\Delta \ell=0, \pm 2$ ) transitions. Therefore, the forbidden transition becomes extremely important for higher- $Z$ elements, whereas the magnetic interaction is generally smaller than the electric interaction.

The M1 transition is characterized by the wavelength $\lambda$, as plotted in Fig. 11 (a) $[37,38]$. The wavelength of the M1 transition is much longer than that of the E1 transition. In particular, the Ti-like M1 transition maintains a constant visible wavelength for $Z>50$, where the L-S coupling gradually changes to the $\mathrm{j}-\mathrm{j}$ coupling. The transition probability changes rapidly with $Z$. For example, the transition probability of the F-like M1 transition increases 

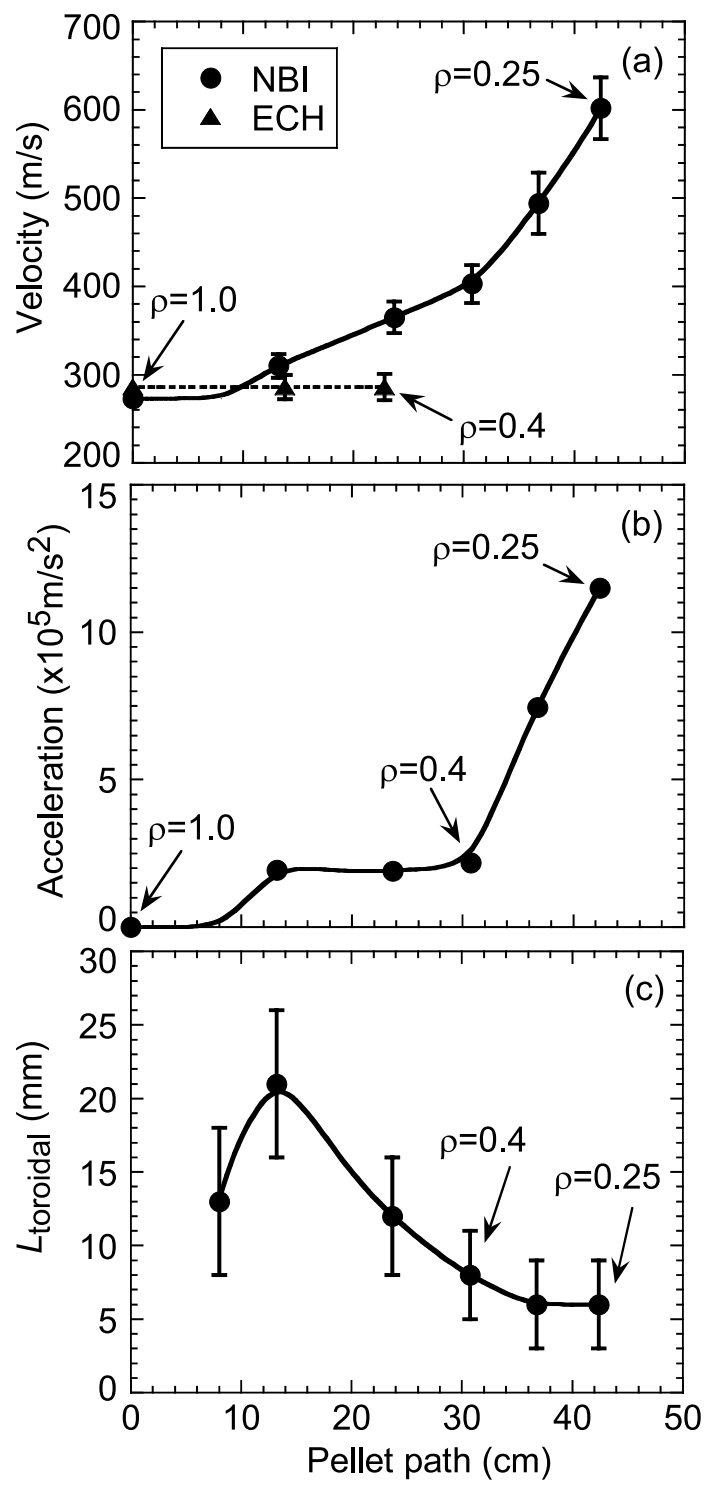

Fig. 10 (a) Measured pellet velocities for ECH (dashed line) and NBI (solid line) plasmas. (b) Calculated pellet acceleration. (c) Measured ablation cloud size in the toroidal direction as a function of pellet path.

as $\mathrm{A} \propto \mathrm{Z}^{12}$, whereas the $\mathrm{E} 1$ transition increases as $\mathrm{A} \propto$ $Z^{3}$. Therefore, the M1 transition is extremely important for plasma spectroscopy when heavier elements must be monitored, e.g., diagnostics of impurities such as Mo or $\mathrm{W}$ in ITER. Studying the M1 transition also contributes to reconstruction of the atomic structure model through exact understanding of the higher terms expressed by Eq. (10).

The M1 transition has been experimentally studied for heavy elements such as $\operatorname{Kr}(Z=36)$, Mo $(Z=42)$, $\mathrm{Xe}(Z=$ $54)$, and $\mathrm{W}(Z=74)$ in the LHD [39-44]. The inert gases are introduced by gas puffing, and the solid materials are injected as an impurity pellet [5,30]. Ti-like XeXXXIII $\left(\mathrm{Xe}^{32+}: 3 s^{2} 3 p^{23} \mathrm{P}_{1-}{ }^{3} \mathrm{P}_{2}\right)$ observed in the visible range is shown in Fig. 11 (b). The M1 transition is generally easily found in the visible range because spectral broadening of the M1 transition is much greater than that of the
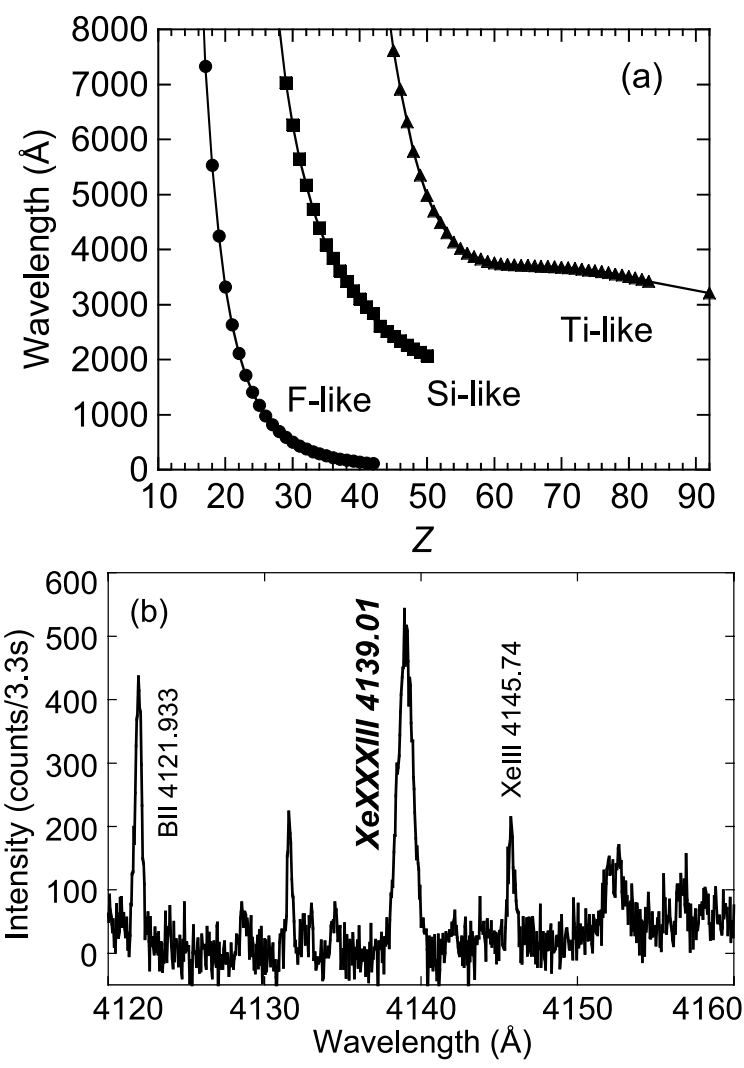

Fig. 11 (a) Wavelength of magnetic dipole forbidden (M1) transitions for F- (solid circles), Si- (solid squares), and Ti-like (solid triangles) isoelectronic sequences as a function of atomic number Z. (b) Ti-like XeXXXIII (4139.01 ̊̊) M1 transitions.

E1 transitions because of the difference in their ionization stages. The M1 transition observed here is carefully identified by reference lines of several E1 transitions existing in the same spectrum.

In the LHD, pure high- $Z$ discharge with a $Z_{\text {eff }}$ value close to the atomic number is possible. A signal intensity sufficient for the study of atomic physics can be easily observed with exposure times within 0.2-1.0 s. Therefore, the experimental error bars in observations of the LHD discharges are quite small compared to those of other experimental devices such as tokamaks and EBITs. Typical examples of the experimental uncertainty are plotted in Fig. 12, which clearly indicates that the error bars of the LHD are remarkably small. The reason is the intensity of M1 transitions among the three light sources. In an EBIT, exposure times longer than $1 \mathrm{hr}$ are normally necessary for recording the M1 transition. In tokamaks, the laser blowoff technique is used instead of the impurity pellet injection used in the LHD. Therefore, the density of impurities is much smaller than in the LHD.

Although relatively old calculations [37, 38] show quite poor agreement with the experimental results, a recent Hartree-Fock approach [48], which includes relativistic corrections with semi-empirical adjustment based on several experimental data sets, agrees well with the present 

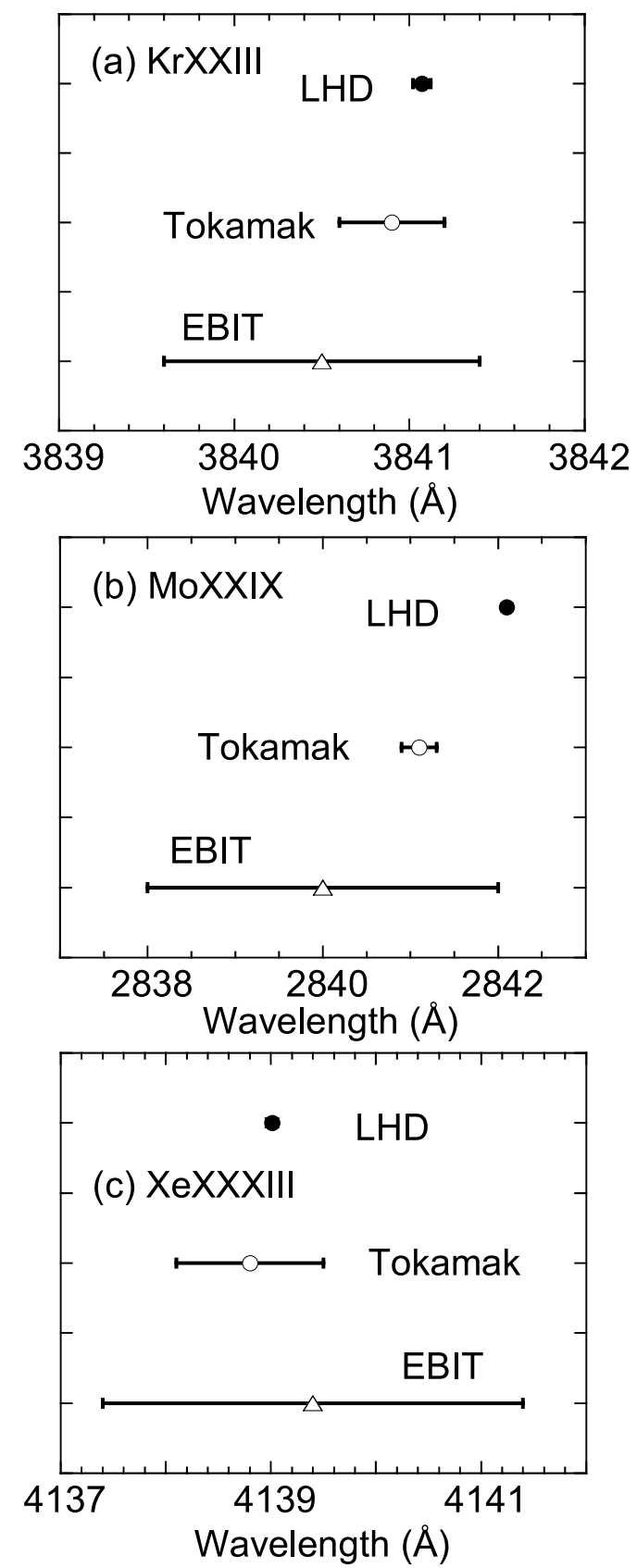

Fig. 12 Typical error bars for the LHD [41], tokamak [37], and EBIT [45-47] in measured wavelengths of the M1 transitions of (a) Si-like KrXXIII, (b) S-like MoXXIX, and (c) Ti-like XeXXXIII.

results, e.g., XeXXXIII. In general, the theory on the M1 wavelength can effectively explain the experimental results for small- $Z$ elements such as Ar because L-S coupling is quite applicable to the atomic configuration. The construction of a good atomic structure model is important for higher- $Z$ elements staying in the transient phase from L-S coupling to $j-j$ coupling.

\section{Summary and Future Directions}

This paper reviews the results of physics experiments closely related to impurities in the LHD. Experimental re- sults related to impurities are caused by the intrinsic nature of the LHD. The present study demonstrates that the LHD plasmas can provide the most favorable circumstances for impurity-related physics experiments. In future work, the three-dimensional structure of impurities will be studied using an imaging EUV spectrometer system in terms of the three-dimensional effect of particle transport and magnetic surface deformation. Information on the three-dimensional impurity structure also becomes important for further detailed study of particle transport in the ergodic layer. The study of the ablation cloud of an impurity pellet, which consists of extremely high-density plasma, is newly begun using fast-response spectroscopy $[49,50]$. Atomic structure will be comprehensively studied using the LHD plasmas, including further investigation of the M1 transition from high- $Z$ elements. Several interesting phenomena have recently been observed after carbon pellet injection and hydrogen pellet injection. We believe that all these topics for future study will bring further progress in impurityrelated physics experiments in the LHD.

\section{Acknowledgements}

The authors thank all the members of the LHD team for their cooperation throughout the LHD operation. This work was partially carried out under the LHD project financial support (NIFS09ULPP527). This work was also partially supported by the JSPS-CAS Core University program in the field of Plasma and Nuclear Fusion.

[1] E. Meservey, M. Bitter, C. Daughney et al., Nucl. Fusion 24, 3 (1984).

[2] E. Meservey, K. Toi, R. Ando et al., Int. Rep. IPPJ-870, Institute of Plasma Physics (1988).

[3] G. Fussmann, A. R. Field, A. Kallenbach et al., Phys. Plasmas Control. Fusion 33, 1677 (1991).

[4] H. Nozato, S. Morita, M. Goto et al., Phys. Plasmas 11, 1920 (2003).

[5] H. Nozato, S. Morita, M. Goto et al., Rev. Sci. Instrum. 74, 2032 (2003).

[6] T. Amano, J. Mizuno and J. Kako, Int. Rep. IPPJ-616, Institute of Plasma Physics, Nagoya University (1982).

[7] H. Nozato, S. Morita, M. Goto et al., Phys. Plasmas 13, 092502 (2006).

[8] H. Y. Zhou, S. Morita, M. Goto et al., Rev. Sci. Instrum. 79, 10 F536 (2008).

[9] H. Y. Zhou, S. Morita, M. Goto et al., Plasma Fusion Res. 5, S1021 (2010).

[10] H. Y. Zhou, S. Morita, M. Goto et al., J. Appl. Phys. 107, 053306 (2010).

[11] Y. Feng, M. Kobayashi, T. Morisaki et al., Nucl. Fusion 48, 024012 (2008).

[12] M. Kobayashi, Y. Feng, S. Morita et al., J. Nucl. Mater. 390-391, 325 (2009).

[13] M. B. Chowdhuri, S. Morita, M. Goto et al., Rev. Sci. Instrum. 78, 023501 (2007).

[14] M. B. Chowdhuri, S. Morita, M. Goto et al., Appl. Optics 47, 135 (2008).

[15] M. B. Chowdhuri, S. Morita, M. Goto et al., Rev. Sci. Instrum. 79, 10F537 (2008). 
[16] M. B. Chowdhuri, S. Morita, M. Kobayashi et al., Phys. Plasmas 16, 062502 (2009).

[17] S. Morita, M. Goto, M. Kobayashi et al., Plasma Sci. Tech. 11, 402 (2009).

[18] C. F. Dong, S. Morita, M. Goto et al., Rev. Sci. Instrum. 81, 033107 (2010).

[19] S. Morita, M. Goto, S. Kubo et al., Nucl. Fusion 42, 1179 (2002).

[20] S. Morita, M. Goto, Y. Takeiri et al., Nucl. Fusion 43, 899 (2003).

[21] Y. Takeiri, S. Morita, K. Tsumori et al., Nucl. Fusion 45, 565 (2005).

[22] Y. Takeiri, S. Morita, K. Ikeda et al., Nucl. Fusion 47, 1078 (2007).

[23] S. Morita and M. Goto, Rev. Sci. Instrum. 74, 2375 (2003).

[24] S. Morita, M. Goto, S. Masuzaki et al., Plasma Sci. Tech. 6, 2440 (2004).

[25] T. Tamano and I. Katanuma, Nucl. Fusion 41, 1803 (2001).

[26] K. Yamazaki, T. Amano, Y. Igitkhanov et al., J. Plasma Fusion Res. 7, 102 (2006).

[27] K. Yamazaki, I. Yamada, T. Oishi et al., J. Plasma Fusion Res. 8, 338 (2009).

[28] K. Y. Watanabe, N. Nakajima, M. Okamoto et al., Nucl. Fusion 35, 335 (1995).

[29] R. Sakamoto, M. Kobayashi, J. Miyazawa et al., Nucl. Fusion 49, 085002 (2009).

[30] R. Katai, S. Morita, M. Goto et al., Jpn. J. Appl. Phys. 46, 3667 (2007).

[31] H. Yamada, K. Y. Watanabe, K. Yamazaki et al., Nucl. Fusion 41, 901 (2001).

[32] S. Morita, R. Sakamoto, M. B. Chowdhuri et al., Proc. 35th EPS Conf. on Plasma Phys., Hersonissos, Greece, 913 June 2008, Vol.32D, P1.105 (2008).

[33] S. Morita, H. Nozato, Y. Takeiri et al., J. Plasma Fusion Res. 79, 641 (2003).
[34] S. Morita, Y. Shirai, M. Goto et al., Nucl. Fusion 42, 876 (2002).

[35] S. Morita, E. Kawatoh, K. Ohkubo et al., Nucl. Fusion 30, 938 (1990).

[36] P. B. Parks, R. J. Turnbull and C. A. Foster, Nucl. Fusion 17, 539 (1977).

[37] V. Kaufman and J. Sugar, J. Phys. Chem. Ref. Data 15, 321 (1986).

[38] U. Feldman, P. Indelicato and J. Sugar, J. Opt. Soc. Am. B 8, 3 (1991).

[39] R. Katai, S. Morita and M. Goto, J. Plasma Fusion Res. SERIES 7, 9 (2006).

[40] R. Katai, S. Morita and M. Goto, Plasma Fusion Research 2, 014 (2007).

[41] R. Katai, S. Morita and M. Goto, Plasma Fusion Research 2, 006 (2007).

[42] R. Katai, S. Morita and M. Goto, J. Quant. Spec. Rad. Trans. 107, 120 (2007).

[43] A. Iwamae, M. Atake, A. Sakaue et al., Phys. Plasmas 14, 042504 (2007).

[44] S. Morita, M. Goto, R. Katai et al., Plasma Sci. Tech. 12, 341 (2010).

[45] H. Watanabe, D. Crosby, F. J. Currell et al., Phys. Rev. A 63, 042513 (2001).

[46] E. Träbert, P. Beiersdorfer, S. Utter et al., Phys. Scr. 58, 599 (1998).

[47] C. Morgan, F. G. Serpa, E. Takacs et al., Phys. Rev. Lett. 74, 1716 (1995).

[48] E. Biemont, E. Träbert and C. J. Zeippen, J. Phys. B 34, 1941 (2001).

[49] M. Goto, R. Sakamoto and S. Morita, Phys. Plasmas Control. Fusion 49, 1163 (2007).

[50] M. Goto, M. Koubiti and S. Morita, J. Phys. B 43, 144023 (2010). 